\title{
G. Verschulden
}

Anders als bei der (objektiven) Sorgfaltswidrigkeit geht es bei der Frage nach dem Verschulden darum, ob den Mitgliedern des Vorstands ${ }^{622}$ bzw. des Aufsichtsrats ${ }^{623}$ die schadensauslösende Handlung auch subjektiv vorgeworfen werden kann. Der Einwand, sie besäßen nicht die notwendigen Fähigkeiten oder Fachkenntnisse im Bereich des Wertpapiermarktes und seien daher für den eingetretenen Vermögensnachteil nicht verantwortlich, steht ihnen nicht offen ${ }^{624}$. Es können jedoch anderweitige Gründe, wie etwa unvorhersehbare gesundheitliche Umstände dazu führen, dass eine Haftung mangels Verschuldens ausscheidet ${ }^{625}$. Vorausgesetzt wird allerdings, dass sich jener Mangel auch auf die Einsichtsfähigkeit auswirkt. Erkennt ein Vorstands- bzw. Aufsichtsratsangehöriger hingegen, dass er krankheitsbedingt nicht mehr in der Lage ist, sein Amt in entsprechender Weise auszuführen, so muss er dieses niederlegen ${ }^{626}$.

In der Praxis werden jedoch nur äußerst selten Situationen auftreten, in denen zwar eine objektive, nicht aber auch eine subjektive Pflichtwidrigkeit eines Organmitglieds vorliegt ${ }^{627}$.

622 Kalss in Kalss/Nowotny/Schauer, Österreichisches Gesellschaftsrecht (2008) Rz. 3/416.

623 Schauer in Kalss/Kunz, Handbuch für den Aufsichtsrat (2010) § 34 Rz. 53.

624 Vgl. dazu allgemein: OGH 10.01.1978, 3 Ob 536/77, SZ 46/113= HS 11.291= HS $11.302=$ HS 11.305 ; OGH 26.02.2002, 1 Ob 144/01k, RdW 2002, $342=$ GES 2002, $26=$ GesRZ 2002, $86=$ ZIK 2002, $92=$ wbl 2002, 325 = ecolex 2003, 34 = SZ 2002/26; Kalss in Doralt/Nowotny/Kalss, Kommentar zum Aktiengesetz ${ }^{2}$ (2012) § 99 Rz. 44; Schauer in Kalss/Kunz, Handbuch für den Aufsichtsrat (2010) § 34 Rz. 53.

625 Vgl. Reischauer in Rummel, Kommentar zum ABGB ${ }^{3}$ II/2a (2007) § 1299 Rz. 5.

626 Hopt in Hopt/Wiedemann, Aktiengesetz Großkommentar ${ }^{4}$ (2008) Band 3, § 93 Rz. 79.

627 Vgl. OGH 26.02.2002, 1 Ob 144/01k, RdW 2002, $342=$ GES 2002, $26=$ GesRZ 2002, $86=$ ZIK $2002,92=$ wbl 2002, $325=$ ecolex 2003, $34=$ SZ 2002/26. 